\title{
Reduksi Produk Cacat pada Produksi Benang dengan Pendekatan Metode Lean Six Sigma
}

\author{
Amelia Munawaroh dan Moses Laksono Singgih \\ Departemen Teknik Industri, Fakultas Tekonologi Industri, Institut Teknologi Sepuluh Nopember (ITS) \\ e-mail: moseslsinggih@ie.its.ac.id
}

\begin{abstract}
Abstrak-Perusahaan amatan adalah perusaahan yang memproduksi benang dan kain. Penelitian ini hanya difokuskan pada Departemen Spinning. Terdapat permasalahan yang terjadi pada departemen tersebut, yaitu adanya pemborosan (waste) dilantai produksi dan adanya complaint dari internal customer yaitu Departemen Weaving. Penelitian ini bertujuan untuk menghitung nilai sigma dari kondisi eksisting dan mengurangi jumlah defect yang berada di lantai produksi. Langkah yang dilakukan dalam penelitian ini disesuaikan dengan framework DMAIC. Fase Define dimulai dari identifikasi kondisi eksisting melalui penggambaran Value Stream Mapping (VSM), activity Classification Diagram, dan penyebaran kuisioner menggunakan AHP untuk identifikasi waste kritis, serta identifikasi dari macam-macam Critical to Quality (CTQ). Pemborosan yang paling sering terjadi pada lantai produksi adanya defect. Fase Measure yaitu dimulai dengan penghitungan nilai sigma dan pemilihan defect yang kritis menggunakan pareto diagram. Dari hasil penelitian rata-rata nilai sigma pada proses produksi benang yaitu sebesar 3,5 sigma. Fase Analyze yaitu dengan dilakukan analisis akar permasalahan adanya defect dengan menggunakan tools Root Cause Analysis (RCA). Setelah itu, dirancang kuesioner Failure Mode and Effect Analysis (FMEA) yang diisi oleh salah satu orang ahli di perusahaan untuk menilai tingkat severity, occurrence, dan detection dari masing-masing akar permasalahan hingga didapatkan nilai Risk Priority Number (RPN). Dari hasil penelitian didapatkan tiga akar permasalahan yang memiliki nilai RPN tertinggi yaitu proses perawatan dan pengecekan komponen mesin produksi benang kurang baik, operator kurang memperhatikan standardisasi dalam peraturan (setting) mesin, dan komponen mesin pada proses produksi mengalami aus. Pada fase Improve dibangun rekomendasi perbaikan sesuai dengan akar permasalahan tersebut. Rekomendasi perbaikan yang diusulkan adalah adanya pembuatan SOP yang baik dan benar serta ditempel pada setiap mesin produksi, pembuatan form pengontrolan kondisi mesin, dan adanya pengadaan pengawas lapangan serta pemberia training secara rutin kepada operator dengan interval 3 bulan sekali. Dengan improvement tersebut, defect dapat direduksi sebesar $45,72 \%$ dan nilai sigma meningkat menjadi 3,77 sigma.
\end{abstract}

Kata Kunci-Analytical Hierarchy Process, Failure Mode and Effect Anlysis, Lean Six Sigma, Root Cause Analysis, Value Stream Mapping.

\section{PENDAHULUAN}

$\mathrm{P}$ ERUSAHAAN Benang (PB) amatan adalah perusahaan yang mengolah bahan baku kapas dan polyester menjadi benang dan bahan jadi kain. Proses produksi pada PB dapat dibagi menjadi dua proses utama yaitu pemintalan (Spinning) dan penenunan (Weaving). Proses produksi pada Perusahaan benang diawali dari Departemen Spinning yang mengolah bahan baku berupa cotton dan polyester menjadi benang, dan selanjutnya diproses menjadi kain oleh
Departemen Weaving. Departemen Spinning adalah Departemen yang sangat berperan penting dalam menghasilkan benang yang berkualitas. Benang yang dihasilkan oleh Departemen Spinning akan berpengaruh pada kain yang diproduksi di Departemen Weaving. Apabila benang yang dihasilkan mengalami cacat dan tetap diolah dalam proses selanjutnya maka akan mempengaruhi kualitas kain. Oleh sebab itu untuk menghindari adanya cacat, akan lebih baik jika cacat tersebut dapat dihindari dan diantisipasi selain dengan proses pengerjaan ulang (rework), karena produk cacat tidak semua akan diproses ulang, hanya 3\% yang akan diproses ulang, sehingga menyebabkan kerugian bagi perusahaan.

Pada penelitian ini penulis akan melakukan peneilitian tentang peningkatan kualitas pada Departemen Spinning B-2 yang memproduksi benang jenis T65/C 45' S. Berdasarkan hasil wawancara awal penelitian, bahwa kualitas dikatakan baik jika sesuai dengan permintaan dan spesifikasi yang diberikan oleh konsumen. Konsumen dari produksi benang adalah produksi kain pada Departemen Weaving (internal customer). Selama ini masih terdapat komplain dari Departemen Weaving terkait kualitas produksi benang.

Selain adanya komplain dari Departemen Weaving yang menandakan adanya produk yang belum memenuhi standar kualitas, terdapat juga material yang cacat pada setiap proses produksi. Namun material tersebut masih bisa diolah kembali (rework) untuk bisa menghasilkan produk yang baik. Dari jumlah defect rate benang, dibuatlah pie chart yang menunjukkan bahwa jumlah cacat dari benang masih belum memenuhi target (Key Performance Indicator) tingkat cacat benang.

Berdasarkan data dari komplain pelanggan yang tidak sesuai dengan spesifikasi oleh Departemen Weaving yang ditunjukkan adanya jumlah produk cacat merupakan indikasi adanya permasalahan terkait adanya pemborosan (waste) yaitu berupa defect. Adanya defect adalah salah satu tanda bahwa dalam mengendalikan kualitas proses produksi yang belum baik.

Salah satu metode yang dapat digunakan untuk mengendalikan dan meningkatkan kualitas produk adalah dengan Six Sigma. Selain itu, salah satu metode untuk mengeliminasi waste berupa defect adalah dengan lean manufacturing [1]. Jika digabungkan maka akan menjadi metode lean six sigma. Dengan diterapkannya metode Lean Six Sigma pada Perusahaan benang amatan, khususnya Departemen Spinning B2 dapat membawa perusahaan berada pada tingkat produk cacat terendah hinga melakukan peningkatan kualitas ke tingkat kegagaln nol (zero defect). 
Metode Lean Six Sigma dapat mengidentifikasi masalah dalam proses produksi dan menguraikan cacat yang membebani dalam hal waktu, uang, konsumen dan peluang. Dalam penelitian ini, fokus produk yang diteliti adalah produk cacat dalam bentuk benang (produk jadi). Selain itu pihak perusahaan ingin mengetahui performansi perusahaan berdasarkan nilai sigma dan menginginkan adanya penerapan konsep Six Sigma. Oleh sebab itu, penelitian mengenai peningkatan kualitas dengan meminimasi jumlah defect perlu dikaji dalam rangka perbaikan yang terus-menerus (continuous improvement) dan untuk mencapai target KPI sehingga terjadi kenaikan nilai sigma dari keadaan sebelumnya.

Adapun tujuan yang ingin dicapai dari penelitian ini adalah sebagai berikut:

1. Menggambarkan proses produksi benang T65/C 45' $\mathrm{S}$ pada Departemen Spinning dengan menggunakan Value Stream Mapping.

2. Mengidentifikasi jenis waste yang paling sering terjadi dalam proses produksi benang.

3. Menghitung nilai sigma level dari proses produksi benang.

4. Mengetahui akar penyebab terjadinya produk cacat.

5. Menentukan alternatif perbaikan untuk mengurangi jumlah produk cacat.

\section{METODOLOGI PENELITIAN}

Metodologi penelitan terbagi menjadi beberapa tahapan. Gambar 1. berikut ini merupakan tahapan-tahapan yang dilakukan selama penelitian:

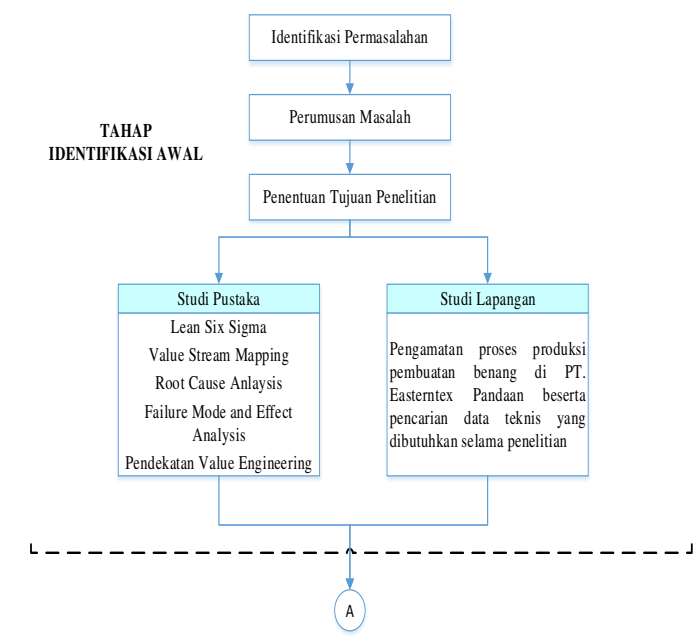

Gambar 1. Metodologi Penelitian.

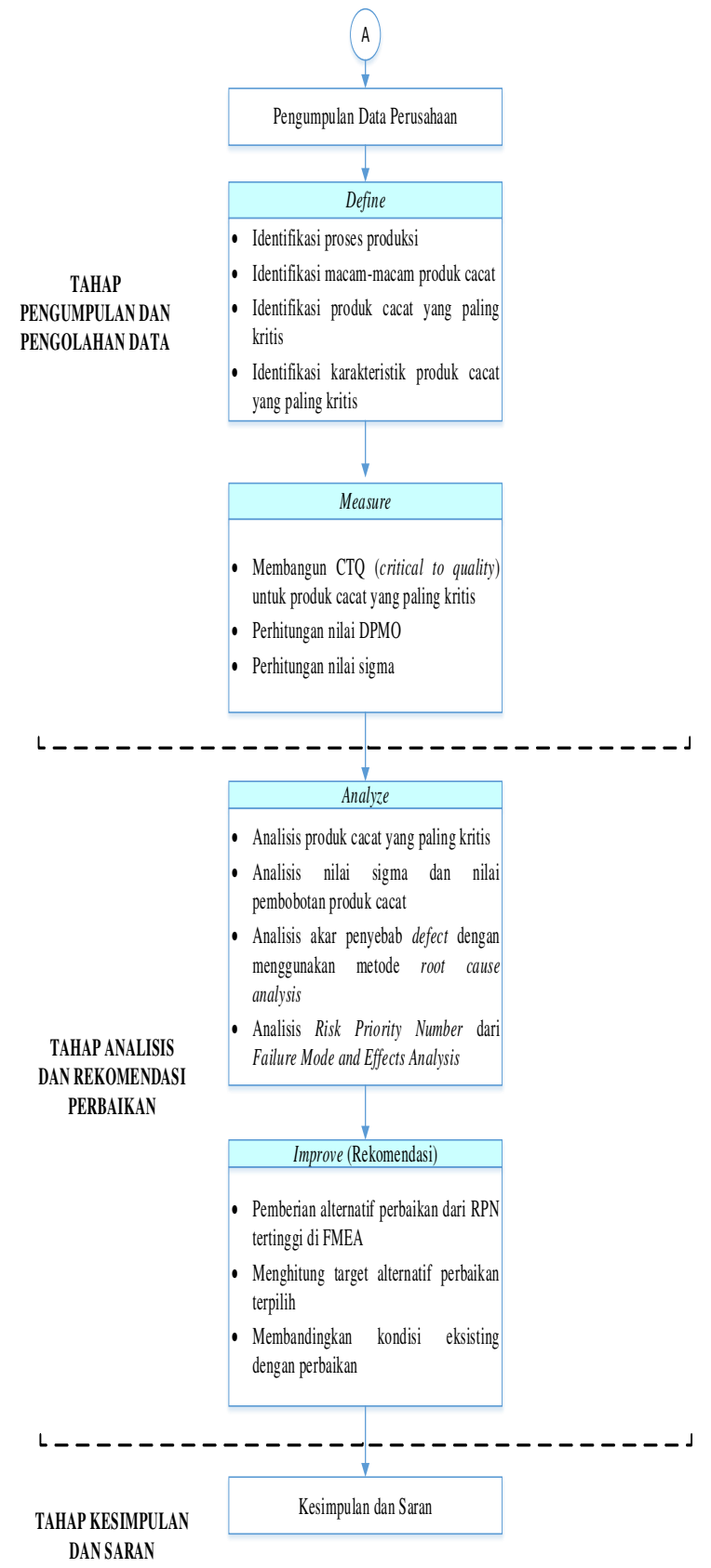

Gambar 1. Metodologi Penelitian (Lanjutan).

\section{PENGUMPULAN DAN PENGOLAHAN DATA}

A. Fase Define

1. Value Stream Mapping

Value Stream Mapping (VSM) adalah sebuah tools yang digunakan untuk membantu penerapan lean manufacturing dalam menganalisa dan mengevaluasi proses kerja tertentu di dalam operasi perusahaan [2]. Aliran dalam VSM terbagi menjadi dua yaitu aliran material dan aliran informasi. Berikut ini merupakan penggambaran Value Stream Mapping secara keseluruhan baik dari aliran informasi maupun aliran fisik produksi benang dapat dilihat pada Gambar 2 . 


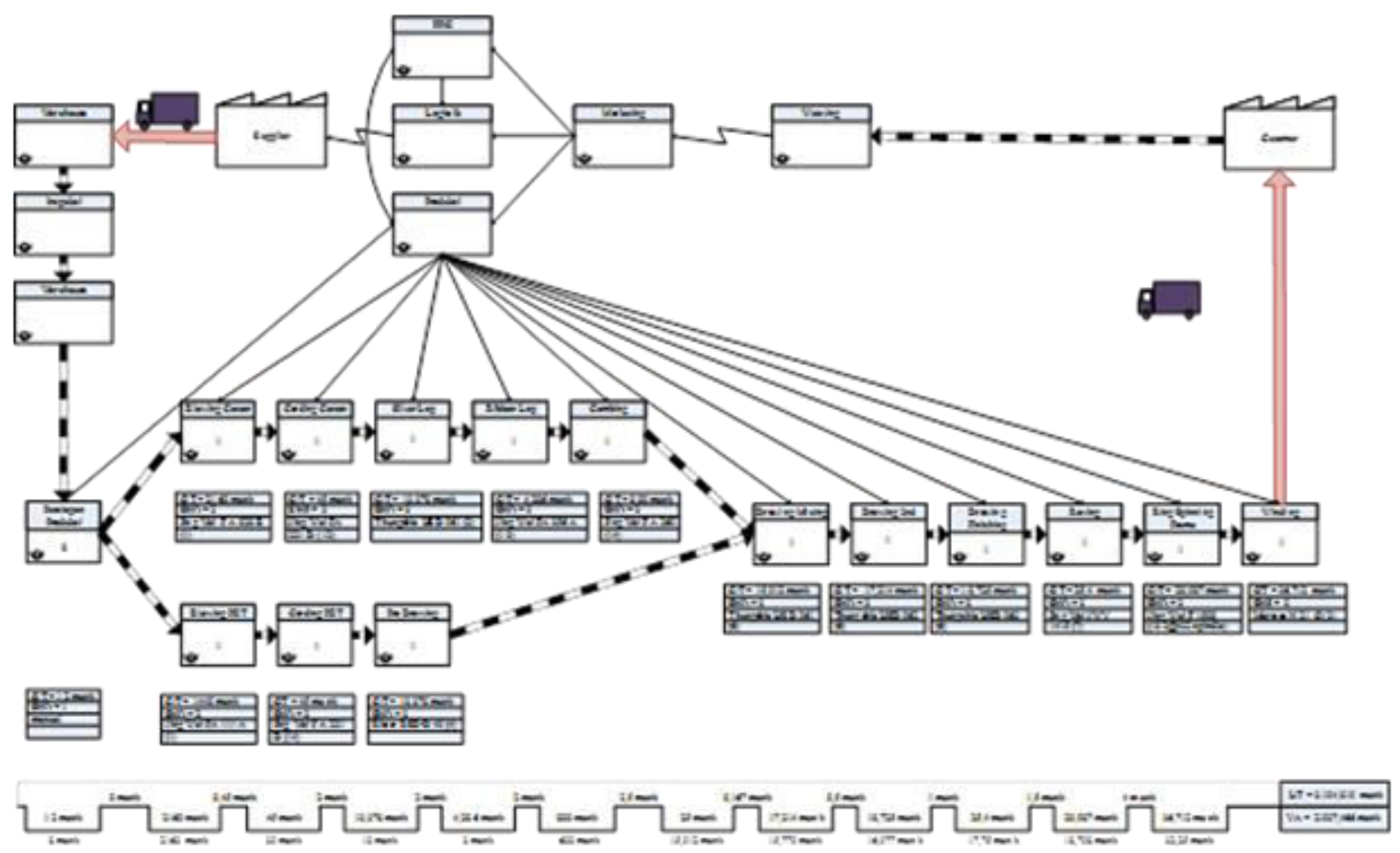

Gambar 2. Value Stream Mapping Produksi Benang.

\section{Identifikasi Waste}

Identifikasi waste dilakukan dengan menggunakan kuisioner AHP dengan bantuan software expert choice. Identifikasi ini bertujuan untuk mengetahui waste manakah yang sering muncul pada sistem produksi benang. Kuisioner diberikan kepada tiga orang responden yang mengerti dan ahli pada bagian produksi dan kualitas benang, ketiga responden tersebut adalah Assistant Manager of Departemen Spinning, Head of Production, dan Head of Quality Control.

Setelah didapatkan nilai pembobotan dari masing-masing responden, maka langkah selanjutnya adalah menghitung ratarata dari ketiga pembobotan tersebut dari masing-masing waste. Berikut ini merupakan rekapitulasi hasil pembobotan dari tiga responden yang dapat dilihat pada Tabel 1 .

Tabel 1.

Rekapitulasi Hasil Kuisioner Identifikasi Waste

\begin{tabular}{llcccc}
\hline \hline \multirow{2}{*}{ No } & \multicolumn{6}{c}{ Waste } & 1 & 2 & 3 & Rata-Rata \\
\hline \multirow{2}{*}{1} & Defect & 0,340 & 0,307 & 0,268 & 0,305 \\
2 & Overproduction & 0,183 & 0,155 & 0,208 & 0,182 \\
3 & Waiting & 0,062 & 0,059 & 0,058 & 0,060 \\
4 & Transportation & 0,077 & 0,077 & 0,068 & 0,074 \\
5 & Unnecessary Inventory & 0,132 & 0,172 & 0,200 & 0,168 \\
6 & Unnecessary Motion & 0,072 & 0,078 & 0,078 & 0,076 \\
7 & Inappropriate Process & 0,134 & 0,152 & 0,120 & 0,135 \\
\hline \hline
\end{tabular}

Berdasarkan hasil rekapitulasi hasil akhir pada Tabel 1 diketahui bahwa waste kritis tertinggi adalah defect dengan porporsi sebesar 0,305 . Waste yang lainnya yang tertinggi adalah overproduction dan unnecessary inventory dengan ratarata bertutut-turut 0,182 dan 0,168 .

3. Definisi CTQ Benang

Identifikasi dari Critical to Quality (CTQ) dilakukan untuk mengetahui berapa jumlah kriteria yang lebih spesifik yang mempengaruhi kualitas sebuah produk.

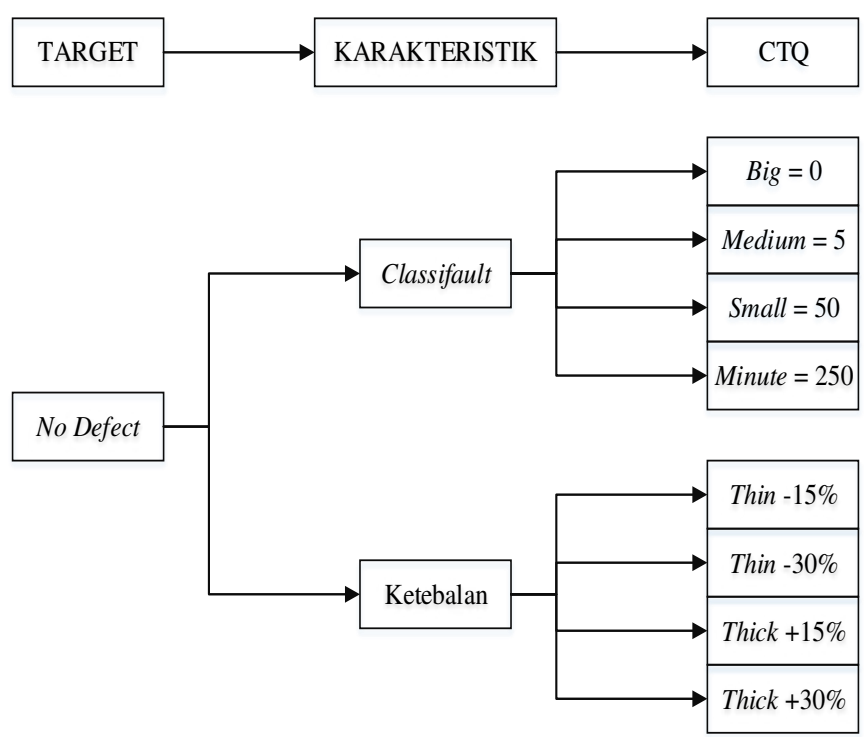

Gambar 3. Definisi CTQ Tree Benang. 
Deskripsi CTQ tree dapat dilihat pada Tabel 2.

Tabel 2.

Definisi CTQ

\begin{tabular}{|c|c|c|c|c|}
\hline Kriteria & Item & Target & Unit & Keterangan \\
\hline \multirow{4}{*}{ Classifault } & Big & 0 & $\begin{array}{c}\mathrm{N} / 100 \\
\mathrm{Km}\end{array}$ & $\begin{array}{l}\text { Slub besar yang ikut } \\
\text { terproses pada benang } \\
\text { (maksimal 0) }\end{array}$ \\
\hline & Medium & 5 & $\begin{array}{c}\mathrm{N} / 100 \\
\mathrm{Km}\end{array}$ & $\begin{array}{l}\text { Slub sedang yang ikut } \\
\text { terproses pada benang } \\
\text { (maskimal 5) }\end{array}$ \\
\hline & Small & 50 & $\begin{array}{c}\mathrm{N} / 100 \\
\mathrm{Km}\end{array}$ & $\begin{array}{l}\text { Slub kecil yang ikut } \\
\text { terproses pada benang } \\
\text { (maskimal 50) }\end{array}$ \\
\hline & Minute & 250 & $\begin{array}{c}\mathrm{N} / 100 \\
\mathrm{Km}\end{array}$ & $\begin{array}{l}\text { Slub paling kecil yang } \\
\text { ikut terproses pada } \\
\text { benang (maskimal 250) }\end{array}$ \\
\hline \multirow{4}{*}{ Ketebalan } & \multirow{2}{*}{ Thin } & -15 & $\%$ & $\begin{array}{l}\text { Ketebalan benang } \\
\text { kurang dari standar } \\
\text { sebesar } 15 \text { persen }\end{array}$ \\
\hline & & -30 & $\%$ & $\begin{array}{l}\text { Ketebalan benang } \\
\text { kurang dari standar } \\
\text { sebesar } 30 \text { persen }\end{array}$ \\
\hline & \multirow{2}{*}{ Thick } & +15 & $\%$ & $\begin{array}{l}\text { Ketebalan benang lebih } \\
\text { dari standar sebesar } 15 \\
\text { persen }\end{array}$ \\
\hline & & +30 & $\%$ & $\begin{array}{l}\text { Ketebalan benang lebih } \\
\text { dari standar sebesar } 30 \\
\text { persen }\end{array}$ \\
\hline
\end{tabular}

\section{A. Fase Measure}

1) Perhitungan Nilai Sigma

Sebelum dilakukan perhitungan nilai sigma, lebih dahulu dilakukan perhitungan nilai DPMO.

$$
\begin{aligned}
\text { a. Tingkat cacat } & =\frac{\text { Jumlah produk cacat }}{\text { Jumlah prduksi }} \\
& =\frac{762,79}{130,91}=0,182102
\end{aligned}
$$$$
\text { b. Jumlah } \mathrm{CTQ}=8
$$$$
\text { c. } \mathrm{DPO}=\frac{\text { Tingkat cacat }}{\text { Banyaknya } \mathrm{CTQ}}
$$$$
=\frac{0,192102}{\mathrm{~g}}=0,0227628
$$$$
\text { d. } D P M O=D P O \times 1.000 .000
$$

$$
=0,0227628 \times 1.000 .000=22762,8
$$

e. Mengkonversikan nilai DPMO menggunakan sigma calculator atau menggunakan tabel sigma.Diketahui nilai rata-rata sigma proses produksi benang adalah 3,5 sigma

2) Penentuan Defect Kritis

Terdapat empat defect yang terjadi pada produksi benang sekaligus yang menjadi komplain dari internal customer, yaitu:

a. Nukeito, adalah benang yang terlalu tipis atau puntirannya terlalu tipis.

b. Itokozu, adalah cone atau fly waste yang masuk ke dalam gulungan.

c. Cut Inside, benang yang terpotong bagian dalam cone. d. Netting, adalah benang yang melintir akibat putusnya benang dan masuk ke dalam gulungan cone

Untuk mengetahui manakah defect yang sangat berpengaruh pda proses produksi benang, maka dilakukan plot data jumlah defect ke dalam pareto diagram. Gambar 4 . merupakan hasil dari pareto diagram.

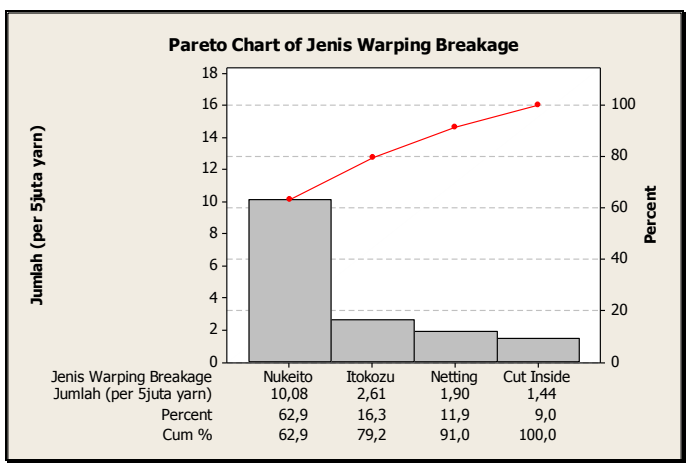

Gambar 4. Pareto Diagram Jenis Defect Produk Benang.

Berdasarkan prinsip 20-80 yang menjadi dasar penentuan keputusan dalam pareto diagram, maka defect yang harus ditangani terlebih dahulu untuk dilakukan improvement adalah defect yang mempengaruhi 80\% darikeseluruhan defect yang ada [3]. Pada Gambar 4. dapat terlihat bahwa jenis defect yang perlu diutamakan dalam penanganan agar berkurang defectnya adalah Nukito dan Itokozu. Nukeito mempengaruhi $62,9 \%$ dan Itokozu yang memepengaruhi $16,3 \%$ dari total defect yang ada pada proses produksi benang.

\section{ANALISA DATA}

\section{B. Fase Analyze}

1) Analisis Akar Penyebab Adanya Defect Menggunakan Root Cause Analysis.

Setelah didapatkan identifikasi waste pada bab sebelumnya, maka langkah selanjutnya adalah menganalisis akar penyebab adanya waste tersebut. Hal itu dapat dilakukan dengan menggunakan 5 whys pada root cause analysis. Root cause analysis merupakan sebuah proses yang dirancang dalam mengidentifikasi dan mengategorikan akar penyebab dengan keselamatan, kesehatan lingkungan, kualitas, keandalan dan dampak produksi dari permasalahan tertentu dengan tujuan membangun dan meimplementasikan solusi yang akan mencegah terjadinya pengulangan masalah [4].

Hasil dari analisa RCA, diketahui terdapat beberapa akar permasalahan penyebab defect Nukeito yang hampir sama. Jika dikemlompokkan secara garis besar, terdapat 3 akar permasalahan yaitu:

1. Part dari mesin pada proses produksi mengalami aus.

2. Proses perawatan dan pengecekan part-part dari mesin produksi benang kurang baik.

3. Operator kurang memperhatikan standardisasi dalam peraturan (setting) mesin.

Selain itu, terdapat juga beberapa akar permasalahan penyebab defect Itokozu yang hampir sama. Jika 
dikelompokkan secara garis besar, terdapat 2 akar

permasalahan yaitu:

1. Proses perawatan dan pengecekan part-part dari mesin produksi benang kurang baik.

2. Operator kurang memperhatikan standardisasi dalam peraturan (setting) mesin.

2) Failure Mode and Effecct Anlysis

FMEA adalah proses identifikasi yang dimulai dari menemukan bentuk kegagalan secara kumulatif dan memberikan skor atau nilai yang telah dikonversi menjadi tiga faktor yaitu Severity, Occurance, dan Detection. Metode FMEA mampu digunakan untuk menemukan kegegalan dengan rinci sehingga kegagalan-kegagalan kritis dapat ditunjukkan dan wajib diantisipasi oleh pihak perusahaan agar bisa segera diatasi [5].

Berikut ini merupakan analisis FMEA untuk waste defect dengan nilai RPN tertinggi.

Tabel 3.

Rangkuman RPN Tertinggi untuk waste defect

\begin{tabular}{|c|c|c|c|c|}
\hline $\begin{array}{l}\text { Potential } \\
\text { Failure } \\
\text { Mode }\end{array}$ & $\begin{array}{c}\text { Potential } \\
\text { Effects }\end{array}$ & $\begin{array}{c}\text { Potential } \\
\text { Causes }\end{array}$ & RPN & Action Taken \\
\hline \multirow[b]{2}{*}{$\begin{array}{l}\text { Nukeito } \\
\text { (puntiran } \\
\text { terlalu } \\
\text { tipis) }\end{array}$} & $\begin{array}{l}\text { Kekuatan } \\
\text { benang diluar } \\
\text { standar yang } \\
\text { ditentukan }\end{array}$ & $\begin{array}{l}\text { Setting } \\
\text { pressure arm } \\
\text { diluar } \\
\text { standadisasi } \\
\text { yang } \\
\text { ditentukan }\end{array}$ & 160 & $\begin{array}{l}\text { Pembuatan } \\
\text { SOP yang baik } \\
\text { dan ditempel } \\
\text { di setiap mesin }\end{array}$ \\
\hline & $\begin{array}{l}\text { Setting kondisi } \\
\text { mesin (Suction } \\
\text { mouth) kurang } \\
\text { tepat sehingga } \\
\text { kondisi mesin } \\
\text { keluar dari } \\
\text { standar yang } \\
\text { ditentukan }\end{array}$ & $\begin{array}{l}\text { Gerakan } \\
\text { suction } \\
\text { mouth rigid } \\
\text { (tidak lancar }\end{array}$ & 180 & $\begin{array}{l}\text { Check suction } \\
\text { mouth semua } \\
\text { mesin winding } \\
\text { dengan } \\
\text { checklist setiap } \\
\text { harinya dan } \\
\text { mengganti } \\
\text { suction mouth } \\
\text { sesuai dengan } \\
\text { jadwal yang } \\
\text { ditentukan }\end{array}$ \\
\hline $\begin{array}{l}\text { Itokozu } \\
\text { (potongan } \\
\text { benang } \\
\text { yang ikut } \\
\text { terproses } \\
\text { pada } \\
\text { gulungan } \\
\text { cone) }\end{array}$ & $\begin{array}{l}\text { Gulungan } \\
\text { dalam cone } \\
\text { kurang rapat } \\
\text { (kendor) }\end{array}$ & $\begin{array}{l}\text { Operator lalai } \\
\text { dalam } \\
\text { memperhatik } \\
\text { an setting } \\
\text { mesin }\end{array}$ & 140 & $\begin{array}{l}\text { Adanya } \\
\text { training yang } \\
\text { rutin yang } \\
\text { dijadwalkan } 3 \\
\text { bulan sekali }\end{array}$ \\
\hline
\end{tabular}

C. Fase Analyze

1) Pemberian Rekomendasi Perbaikan Mengacu pada Hasil RPN Tertinggi FMEA

a. Pembuatan SOP yang baik dan ditempel di setiap mesin.

Proses pada suatu pekerjaan harus dirancang dan dikembangkan secara tersruktur dan sistematis. Tujuan dari pembuatan SOP yang baik akan memudahkan setiap operator mengoperasikan mesin dengan benar dan mencegah terjadinya kecelekaan kerja serta tidak tercapainya target produksi. Setiap SOP dari job standard dalam mengoperasikan mesin ditempel pada setiap mesin agar setiap operator selalu membaca dan mengingat SOP yang baik dalam mengoperasikan mesin.

b. Pembuatan form pengontrolan keadaan komponen mesin.

Pembuatan form ini adalah agar keadaan komponen mesin dapat dikontrol dengan mudah baik oleh bagian pemeliharaan maupun leader. Adanya form ini merupakan salah satu cara untuk mengurangi kemungkinan adanya kerusakan yang terjadi pada komponen mesin secara preventive maintenance. Selain itu banyaknya defect yang disebebkan karena komponen mesin aus dapat juga diatas dengan langkah preventive maintenace pemberian warna/tanda pada komponen. Pemberian tanda pada komponen mesin bertujuan agar operator dapat dengan mudah mendeteksi jika suatu komponen sudah mengalami aus akibat seringnya komponen tersbut mengalami getaran. Sebagai contoh pemberian warna biru yang menandakan adanya kerusakan pertama kali, warna kuning yang menandakan adanya kerusakan kedua kali, dan merah yang menandakan adanya kerusakan ke-tiga dan seterusnya hingga pemberian warna khusus jika menandakan komponen sudah wakunya untuk diganti (replacement).

c. Pengadaan training kepada operator.

Pengadaan training ini akan menekankan kepada setiap operator akan pentingnya mengoperasikan mesin sesuai dengan standar yang ditentukan dan selalu memperhatikan safety. Training dilakukan oleh pihak dalam atau ketua bagian shift kepada setiap operator shift, sehingga tidak memerlukan biaya tambahan untuk membayar trainer.

Paradigma lama membuat setiap operator berfikir bahwa operator hanya bekerja sebagai pemakai mesin saja tanpa memperhatikan tujuan dari departemen. Diharapkan materi dalam training akan mengubah cara berfikir operator bahwa operator tidak hanya sebagai pemakai saja namun juga memperhatikan kerusakan dan kulitas produk yang dihasilkan serta bisa mencapai target jumlah produksi departemen.

Materi yang akan ditekankan dalam training diantaranya adalah sebagai berikut:

1. Pengetahuan dasar tentang mesin yang akan dioperasikan

2. Bagaimana cara mengoperasikan mesin sesuai dengan SOP

3. Safety First (Sisha Koso)

4. Perawatan dasar tentang mesin yang akan dioperasikan

Dengan adanya minimal keempat materi tersebut, diharapkan setiap operator yang rutin melakukan dapat melakukan pencapaian dari adanya training yang meliputi:

1. Mengetahui lebih awal adanya bunyi yang aneh, sepeti suara vibration komponen mesin karena kecepatan mesin terlalu besar atau yang lainnya.

2. Mengetahui lebih awal kendornya komponen mesin, sehingga mereduksi unplanned maintenance.

3. Selalu membersihkan adanya lapping pada mesin. Tidak mebiarkan adanya waste khususnya defect menumpuk terlalu banyak sehingga mengganggu operasi kerja mesin karena mesin dalam keadaan kurang bersih.

Dalam pemberian training akan diberlakukan sistem reward dan punishment. Adanya sistem reward akan diterapkan kepada operator yang mempunyai skill dan tanggung jawab yang tinggi terhadap job standard yang dioperasikan.

Adanya sistem punishment akan diterapkan jika operator yang sudah melakukan training namun tertangkap telah melakukan kesalahan yang merugikan perusahaan seperti adanya pemborosan (waste) yang berlebihan karena keteledoran operator. 
2) Target Perbaikan Altenatif Terpilih

Berdasarkan pengolahan data pada bab sebelumnya rata-rata per periode adalah $127,86 \mathrm{Klbs}$. Dengan dilakukannya diskusi dengan pihak perusahaan yang ahli dalam bagian produksi, quality control dan maintenance, ketiga rekomendasi perbaikan yang diusulkan akan mampu mereduksi defect sebesar $45,72 \%$ sehingga total defect per periode akan berkurang sebesar 58,48 Klbs.

Setelah adanya rekomendasi perbaikan maka target dalam menurunkan defect sebesar 58,48 $\mathrm{Klbs}$, maka nilai sigma otomatis akan naik. Nilai sigma setelah perbaikan meningkat sebesar 0,22 sigma sehingga menjadi 3,77 sigma.

\section{KESIMPULAN}

Kesimpulan yang dapat ditarik dari tujuan penelitian ini adalah:

1. Pada proses bisnis pembuatan benang dengan menggunakan Value Stream Mapping, dapat diketahui cycle time sebesar 3.194,819 menit, dan value added activity hanya sebesar 2.937,466 menit.

2. Dari identifikasi jenis defect, terdapat empat jenis defect yang menyebabkan benang menjadi defect yaitu Itokozu, Cut Inside, Nukeito dan Netting. Dari ke-empat tersebut yang manjadi defect yang paling kritis adalah Nukeito dan Itokozu.

3. Nilai sigma rata rata dari proses produksi benang $\mathrm{T} 65 / \mathrm{C}$ 45'S selama 12 periode adalah sebesar 3,5 sigma.
4. Akar penyebab adanya defect diantaranya adalah proses perawatan dan pengecekan part-part dari mesin produksi benang kurang baik, operator kurang memperhatikan standardisasi dalam peraturan (setting) mesin, dan komponen dari mesin pada proses produksi mengalami aus.

5. Terdapat tiga alternatif perbaikan untuk mengurangi jumlah defect, yaitu pembuatan SOP yang baik dan ditempel di setiap mesin disertai adanya pengawasan dari atasan untuk mengawasi kinerja operator, pengecekan part-part mesin yang berada di lantai produksi dengan adanya checklist setiap harinya dan mengganti part mesin yang sudah rusak atau sudah masa pakainya habis, dan pengadaan training yang rutin kepada operator yang dijadwalkan 3 bulan sekali dan pemberian reward dan punishment. Dengan adanya rekomendasi perbaikan nilai sigma meningkat menjadi 3,77 sigma.

\section{DAFTAR PUSTAKA}

[1] M. L. George, Lean Six Sigma, Combining Six Sigma Quality With Lean Production Speed. Spring: McGraw-Hill Professional Publishing, 2002.

[2] S. . Poling and M. . Nash, Maping The Total Value Stream-A comprhensive Guide for Production and Transactional Processes. New York: Taylor \& Francis Group, 2008.

[3] Singgih, L. Moses, and Renanda, "Peningkatan Kualitas Produk Kertas dengan MEnggunakan Pendekatan Six SIgma di Pabrik Kertas Y," Surabaya, 2008.

[4] J. Rooney and L. Heuvel, "Quality Basics - Root cause analysis for Beginners," 2004. [Online]. Available: www.asq.org.

[5] P. Keller and T. Pzydek, The Six Sigma Handbook, 4th ed. McGraw-Hill Professional Publishing, 2010. 